\title{
Corrupción y desarrollo humano: un estudio de correlación entre fenómenos político-sociales
}

\section{Corruption and human development: a correlation study between political-social phenomena.}

\author{
Corrupção e desenvolvimento humano: um estudo \\ de correlação entre fenômenos político-sociais
}

JUNIOR SARMIENTO

Universidad Federal de Alagoas, Brasil

RECEPCIÓN: O7/O4/2015 • ACEPTACIÓN: 30/05/2015

RESUMEN La corrupción es un fenómeno es relevante, prácticamente, para todas las sociedades, en mayor o menor escala. Los actos de corrupción están vinculados a la sobreposición de intereses públicos por los privados con una serie de acciones ilegales concretas que afectan directamente las políticas públicas y la efectividad de la administración pública. A través del índice de correlación de Pearson se constató que la corrupción y el desarrollo humano poseen una fuerte correlación, percibiéndose una tendencia lineal de factores inversamente proporcionales. Pero, esos fenómenos son potenciados por la efectividad o ausencia de accountability, la corrupción, claramente, se vuelve más fuerte cuando hay una precariedad en el intrumento de accountability, ya que cuando ese instrumento se muestra efectivo la promoción de la justicia social y la democracia son fortalecidas y, consecuentemente, hay desarrollo humano.

PALABRAS CLAVE Corrupción, desarrollo humano, accountability, corrección. 
ABSTRACT Corruption, on a greater or lesser scale, is an important phenomenon for practically all societies. Acts of corruption occur when private individuals place their own interests above those of society in a series of concrete illegal acts which directly affect public policies and the effectiveness of public administration. Using a Pearson correlation index we found that there is a strong correlation between corruption and human development, in a linear trend of inversely proportional factors. However these phenomena are affected by the effectiveness or absence of accountability. Corruption, clearly, becomes stronger when the instrument for accountability is weak, since when this instrument is seen to be effective the promotion of social justice and democracy is strengthened, and consequently there is human development.

KEYWORDS Corruption, human development, accountability, correction.

RESUMO A corrupção é um fenômeno que atinge praticamente todas as sociedades, em menor ou maior escala. Os atos corruptos estão vinculados a sobreposição do interesse público pelo privado com a concretização de ações revestidas de ilegalidade afetando diretamente as políticas públicas e a efetividade da administração pública. Através do índice de correlação de Pearson constatou-se que a corrupção e o desenvolvimento humano possuem uma forte correlação, percebendo uma tendência linear de fatores inversamente proporcionais. Mas, esses fenômenos são potencializados pela efetividade ou ausência da accountability; a corrupção, claramente, torna-se mais forte quando há uma precariedade no instrumento de accountability, já quando esse instrumento mostra-se efetivo a promoção da justiça social e a democracia são fortalecidas e, consequentemente, há o desenvolvimento humano.

Palavras chave Corrupção, Desenvolvimento Humano, Accountability, Correlação.

\section{Introdução}

Quando se fala de corrupção, o cidadão comum associa o fenômeno como culpa de outrem que se aproveita dos seus status econômicos e sociais em benefício próprio em detrimento do bem comum. Há uma delimitação natural na avaliação da corrupção, pois os meios ilícitos geralmente estão camuflados 
e apenas quando descobertos, a população tem conhecimento dos fatos. E, como há dificuldades em descobrir todos os atos corruptos, os órgãos de controle (accountability horizontal) utilizam-se de ferramentas e métodos para levantamento de evidências que possam configurar as práticas ilícitas, passivas de punição. Segundo Avritzer et al (2008), a corrupção acontece quando alguém, na busca de seus interesses pessoais, age de forma pérfida, burlando as normas estabelecidas. $\mathrm{O}$ foco não é a repressão dos interesses pessoais, pois em algum grau sempre haverá a existência dos interesses privado, mas a utilização de mecanismos que prejudiquem o interesse coletivo e o bem comum por meios escusos.

Ao longo dos anos, tenta-se minimizar o fenômeno através de marcos regulatórios e criação de organismos de accountability. Avritzer et al (2008) complementa que a transparência das informações é uma ferramenta indispensável para o controle social em uma democracia representativa, pois auxilia o combate à corrupção e aproxima a população dos atos e fatos políticos. Percebe-se, que a delimitação do poder através de normas e leis, mecanismos e órgãos paralelos é um procedimento adotado historicamente no "controle» dos poderes concedidos pelo meio econômico e político e, não obstante, o cidadão precisa atuar ativamente como agente fiscalizador e transformador na tentativa de garantir a execução de políticas públicas efetivas que visam o bem-comum. E, quando se fala em bem-comum, as políticas públicas são importantes para a inclusão da população mais pobre e garante por meio de «liberdades instrumentais» o desenvolvimento humano com uma maior justiça social (Rawls, 2000).

Porém, apesar de um tema recorrente entre a mídia e a população, falta literatura científica atualizada que trate sobre o fenômeno corrupção, suas reais implicações, variáveis, medidas preventivas eficientes entre outros. As formas de identificação da corrupção ainda dependem muito da visibilidade dos escândalos e isso torna o processo de avaliação de corrupção um tanto quanto subjetivo. Além disso, é preciso realizar o cruzamento de dados com demais dimensões e variáveis para identificar suas causas e os efeitos; especificamente na relação com a renda, saúde educação — base de cálculo para o índice de desenvolvimento humano.

Observa-se que o conhecimento produzido sobre o tema, muitas vezes é tratado de forma pontual, com um curto espaço temporal e com uma amostra estratificada que pode gerar alguns vieses. Tais escolhas podem gerar uma pesquisa «míope» e os resultados encontrados podem não retratar a realidade. 
Portanto, a presente pesquisa utiliza o lapso temporal de um (I) quadriênio com uma amostragem de I7 I países. E, tendo em vista que nenhum outro estudo contempla essa amplitude de informações, é aplicado o método quantitativo a fim de obter dados objetivos correlacionando as afirmações teóricas com os resultados estatísticos obtidos.

Com isso, a pesquisa tem como objetivo principal analisar a seguinte hipótese: «Existe uma forte correlação entre corrupção e o desenvolvimento humano». O estudo utiliza métodos estatísticos para obtenção dos resultados, com ênfase no valor obtido através do Coeficiente de Correlação de Pearson e a Regressão Linear.

Como objetivos específicos, tem-se a análise de perspectiva histórica da corrupção nas macrorregiões, evidenciar o grau de corrupção institucionalizada e análise das demais variáveis qualitativas com impacto na corrupção.

Devido ao grau de importância do tema que abrange o interesse de toda a população, o presente trabalho demonstra-se viável para apreciação de pesquisadores, acadêmicos, gestores públicos, empresários e toda a sociedade civil.

\section{Revisão de literatura}

\section{Conceito e aspectos históricos da corrupção}

Primeiramente, é importante esclarecer que definir corrupção é um desafio, pois delimitar a palavra é considerar que tal fenômeno é imutável e estático ao longo do tempo e, ao consider os aspectos históricos, a própria palavra corrupção possui vários significados e conotações, não se mostra viável delimitar através de um único conceito o que seria corrupção (Heidenheimer e Johnston, 2002). Weber (1962) afirma que não se deve começar com uma definição, mas obter aspectos e exemplos específicos para um conceito que, porém, pode ser alterada ao decorrer do tempo. A partir dessa afirmação, serão explanadas as ideias dos principais estudiosos do assunto e evolução da corrupção.

Os estudos sobre corrupção vêm sendo, a cada dia mais relevantes e, apesar de não ser o centro dos trabalhos dos cientistas sociais, a questão sobre as implicações da corrupção no desenvolvimento político-sócio-econômico vendo sendo cada vez mais abordadas (Heffernan e Kleinig, 2004). Mesmo com tal relevância, a tentativa de delimitação da palavra através de um conceito mostra-se um desafio por ser tratar de um fenômeno que varia entre as sociedades e momentos históricos. O filósofo Aristóteles (2OI2) Retrata corrupção 
através da tipologia de governo e seus respectivos desvios de finalidade do bem comum e sobreposição dos interesses privados (de um pequeno grupo) aos interesses públicos. O pensador Maquiavel (2009) trata corrupção como fenômeno latente na política diante do poder concebido pela mesma, sendo possível apenas medidas retardatárias do acontecimento do fenômeno. Os grandes pensadores de outrora relacionavam a corrupção com os atos advindos dos governantes ou a cúpula que exercia poder sobre assuntos públicos. Weber (apud Motta, 2004), no campo organizacional —administração burocrática-, trata da estrutura como meio de manter a legalidade e cumprimento das regras, separando os interesses públicos (organizacionais) do privado, ou seja, uma evolução do patrimonialismo -fragilmente corruptível- para um sistema regrado de maior controle.

Já a partir da segunda metade do século XX, os casos de corrupção de grande repercussão em vários países e diversas áreas foram surgindo e, com isso, a necessidade de estudos mais aprofundados, com uma nova visão e conceito e consequência.

Como marco dos estudos consagrados, podemos citar um dos grandes estudiosos do tema, Huntington (1973) explica sobre a necessidade da distinção entre o interesse público e privado, pois quando não há essa distinção é impossível determinar o que ou não corrupção. $\mathrm{O}$ autor retomou a ideia entre público e privado, deixando clara a obrigação do Estado e dos particulares. Outra grande contribuição acerca do tema pode ser atribuída também a Huntington (I973), que reforça a corrupção como fenômeno latente e que surge mais fortemente em períodos de crescimento e modernização acelerados, devido ao aumento da riqueza e poder. $\mathrm{O}$ estudioso aborda uma visão condicionante para o surgimento da corrupção com foco no contexto econômico. Outra brilhante estudiosa sobre o tema foi Rose-Ackerman (I978, p. 6-7):

An act is commercially corrupt if a member of an organization uses his/ her position, his/her rights to make decisions, his/her access to information, or other resources of the organization, to the advantage of a third party and thereby receives money or other economically valuable goods or services where either the payment itself or the services provided are illegal and/or against the organization's own aims or rules.

A autora retrata da relação de interesse entre os envolvidos no fenômeno da corrupção, onde um lado utiliza, geralmente, a vantagem política ou técnica e 
o outro lado o poder financeiro. A abordagem de Rose-Ackerman é comportamental correlacionada aos agentes que se beneficiam da corrupção, denominados de rent-seeking. Rose Ackerman (I978) atribui, também, a corrupção aos incentivos do «sistema» que funcionam como catalisadores do fenômeno, permitindo aos agentes políticos maximizarem o suborno ou propina. Cockcroft (20I2) cita ainda que o agente político não é o rent-seeking, empresários e burocratas estão constantemente ligados ao fenômeno agindo de forma passiva ou ativa, dependendo da posição ocupada, recursos disponíveis e objetivos.

Em sua obra, Klitgaard ( 1994, p.38) cita que corrupção é: «a indução por meio de considerações impróprias a cometer uma violação do dever. Heidenheimer e Johnston (2002) definem corrupção como termo geral que abrange abuso de autoridade na espera de ganhos pessoais, monetários ou não. Porém, aprofundando-se no tema, Heidenheimer (I970) agrupa em três os tipos básicos de definição mais utilizadas por estudiosos no assunto: I) uma definição centrada no ofício público, essa definição parte da corrupção do desvio dos deveres formais do cargo de um funcionário público, devido à busca de recompensas para si ou para terceiros; 2) uma definição centrada no mercado, que tem como fator preponderante para a corrupção a maximização da renda, ou seja, o fator da renda pessoal; 3) uma definição centrada na ideia de bem público, segundo essa definição, uma prática é considerada corrupta quando o interesse comum é violado em função da preocupação com ganhos particulares.

Tradicionalmente, os escândalos de corrupção que envolve agentes políticos têm suas consequências suprimidas com uma tendência protecionista aos corruptores do alto escalão político, como lembra Gingerich (2006), que todos os atores da corrupção têm interesse em ocultar ou revelar escândalos, o fator determinante para a escolha geralmente é a avaliação dos ganhos x perdas. Habermas (2002) observa que a neutralidade do direito - e do procedimento democrático de privação do direito- é ocasionalmente entendida como se questões políticas de natureza ética tivessem de ser afastadas da agenda política por meio de «gag rules» e suprimidas das discussões por serem inacessíveis a uma regulamentação jurídica imparcial.

A partir dos casos concretos de corrupção e envolvimento de agentes políticos, tornam-se necessários mecanismos de prevenção ou remediação do problema. Porém, quando o «sistema» é apático quanto ao combate de práticas dessa natureza, cria-se um ambiente favorável para práticas antiéticas.

Até então o foco para entendimento da corrupção foi a relação humana 
através do prisma político-econômico. Porém, há autores que tratam esse fenômeno, também, através do prisma cultural, reforçando as questões dos valores éticos e morais. Avritzer et al (2008) relata que as diferenças culturais, do ponto de vista de pesquisas comparativas, mostram que a corrupção é variável conforme o plano de valores. Pareto (I984) afirma que a diferença entre os países será identificada, substancialmente, no sentimento do povo (valores), ou seja, um povo honesto gera um governo honesto.

A conjuntura de todos os fatores explanados é decisiva para o acontecimento do fenômeno, o poder político, econômico e social. Nesse sentido, partir-se do pressuposto de que esses sistemas interagem de forma permanente, e que nenhum deles funciona de forma independente (Alves, 2009). Dessa forma, não se pode também analisar a corrupção apenas por um enfoque, tem-se que levar em consideração todo o contexto e sistema para entendimento do fenômeno.

Transferindo todos os ensinamentos para a atualidade, tem-se a responsabilidade direta do poder público - técnico ou político- no cumprimento legal de servir ao interesse público, evitando sempre a sobreposição do interesse privado sobre o público (Nogueira, 2005). E, sendo a corrupção «regulável», é importante levantar os meios utilizados para esse controle.

\section{Accountability como instrumento de combate à corrupção}

Nesse tópico, apesar da importância do tema, não será abordado diretamente o conceito, mas sim as características e implicações, pois há grande dificuldade em conceituar a palavra, como relata Behn (200I, p.3): «accountability is an important yet elusive concept whose meaning and characteristic differ depending upon of context.»

O dicionário da língua inglesa conceitua accountability como qualidade ou estado de ser responsabilizado, ou seja, a imputação da obrigação em responder por algo. Contudo, o mais desejável é obter a noção, ao invés da definição, já que o assunto faz parte das ciências social, que se transforma ao longo do tempo.

Na mesma obra Behn (200I) cita que accountability pode ser utilizada de formas distintas quando ligadas a finanças, equidade, performance e entre outros. Além disso, os objetivos e meios específicos são diferentes entre si. É preciso frisar que para alguém tenha a obrigação de responder ou prestar conta, deve haver alguém que responsável pela solicitação e verificação. Behn (200I) 
destaca que existe dois grupos:

- Accountability Holders: pessoas, órgãos, organizações que fiscalizam, verificam as ações dos holdees; $e$

- Accountability Holdees: tem o dever de «prestar contas» aos holders.

Para que haja o processo de Accountability é preciso definir de quem é a responsabilidade das informações e a quem será informado. Geralmente, a responsabilização recai sobre aquele (pessoa física ou jurídica) que recebe algum benefício pecuniário ou não, enquanto o direito e a percepção da necessidade de receber o report fica a cargo dos stakeholders. Behn (200I) cita «everyone wants —other people- to be held accountable». Essa afirmação é visível em todas as áreas, política, organizacional e social, uma vez que todo direito traz consigo a imputabilidade, ou seja, a punição pelo mau uso desse direito.

É importante ressaltar que a accountability, assim como a punição, depende do tipo de accountable. Como explica O'Donnel (I998), existem dois tipos de Accountability: I) accountability horizontal, que diz respeito ao controle de órgãos governamentais e 2) accountability vertical, quando cidadãos ou um grupo da sociedade civil, de forma organizada, exercem essa ação de controle ou «punição".

Para facilitar a compreensão, tem-se como exemplo nacional de accountability horizontal, o Tribunal de Contas da União e dos Estados exercem essa função de verificação da aplicação de recursos por parte de órgãos da administração direta e indireta e, quando necessário, há a punição dos agentes públicos pela má utilização desses recursos. Já a accountability vertical, geralmente é exercida pelos cidadãos de forma avulsa e, quando não organizada, se mostra frágil tornando um dos seus poderes de punição ineficaz - o voto. Mas, um fator é primordial para o alcance da accountability: a informação. E, além da organização, é necessária a percepção da população nesse processo para efetivação da democracia que, segundo Dahl (200I) corresponde a participação, igualdade, conhecimento, controle e inclusão de forma indissociável e permanente. No que diz respeito ao governo - decisões políticas-, sua contribuição pode acontecer em duas frentes, segundo Avritzer et al (2008):

I) Reforçar o princípio da virtude cívica, por meio da promoção de incentivos à participação política e de ferramentas que facultem a interação entre arenas participativas e representativas, diminuindo a assimetria informacional entre representantes e representados; 2) podem ser dissua- 
sórias relativamente à prática da corrupção, através da organização de mecanismos que aumentem a publicidade dos atos e das omissões dos governantes ou através da efetivação de instrumentos de punição que tornem proibitivos os custos da corrupção e incertos os seus benefícios.

Como foi explanado acima, a informação sistematizada e atualizada é um forte aliado, pois funcionam como uma ponte entre os accountability holders e accountability holdees. A informação é considerada um meio de «transparência» dos atos e fatos pertinentes, sendo um método de prestação de contas e medida de combate a corrupção.

Segundo Bobbio (I986), "escândalo é a corrupção que vem a público». Portanto dar publicidade à corrupção é uma medida de combate a essas práticas. Dessa forma, a imprensa torna-se peça fundamental para a formação da percepção do nível de corrupção. É imprescindível que todo o trabalho da imprensa, quanto a veiculação da informação, seja imparcial e retrate de forma fidedigna todos os fatos. Avritzer et al (2008) relata que os escândalos midiáticos representam a ação de controle social mais saliente em termos de luta contra a corrupção, pois permitem dar conhecimento à opinião pública.

Toda essa discussão sobre accountability e combate à corrupção tem um fim de promover a justiça social, onde em uma sociedade democrática, todos os serem humanos são dignos e têm a mesma importância. Por isso, possuem direitos e deveres iguais não apenas em aspectos econômicos, mas também relativos à saúde, educação, trabalho, direito à justiça e manifestação cultural.

Justiça social, liberdade e desenvolvimento humano

Através da justiça social, é possível diminuir drasticamente as diferenças de oportunidade, aumentando a potencialidade do ser, já a inexistência dessa igualdade vai na contramão da liberdade e, consequentemente, do desenvolvimento do indivíduo. Como esclarece Sen (20I0), toda forma de privação de capacidade é considerada como uma perda da amplitude da liberdade pessoal. Tem-se como exemplo: fome, analfabetismo, doenças físicas e mentais. Segundo Sen, essas capacidades representam a «liberdade substantiva», que permitem um maior leque de escolhas para cada indivíduo.

Sen (20IO) reforça que a expansão das «capacidades» pode ser aumentada pela política pública, mas também, pode ser influenciada pelo uso efetivo das capacidades participativas do povo. O autor também cita que as «liberdades 
instrumentais» devem ser consideradas no processo social de desenvolvimento pois estão relacionadas às liberdades políticas, às facilidades de mercado e às oportunidades sociais. Ou seja, A justiça social só é alcançada através das «liberdades instrumentais» que condicionam a «liberdade substantiva»e, assim, potencializar o desenvolvimento humano.

Essas implicações levantas por Sen, de certa forma, são complementares às ideias de Rawls (2000), que parte de uma concepção geral de justiça baseada na ideia de que todos os bens primários - liberdades, oportunidades, riqueza e entre outros-, devem ser distribuídos de maneira igual ou compatível com o sistema semelhante. Rawls (2000) argumenta que os "princípios de justiça» emergem na posição original através de um acordo unânime:

- Cada pessoa tem um direito igual a um esquema plenamente adequado de liberdades básicas iguais que seja compatível com um esquema similar de liberdade para todos;

- As desigualdades sociais e econômicas devem satisfazer duas condições. Primeira, elas devem estar associadas a cargos e posições abertos a todos em condições de igualdade equitativa de oportunidades. Segunda, elas devem ser para o maior benefício dos membros menos favorecidos da sociedade

Fica claro que a visão da liberdade adotada envolve tanto os processos que permitem a liberdade de ações e decisões como as oportunidades reais que as pessoas têm, dadas as suas circunstâncias pessoais e sociais. E, assim como há a expansão da capacidade, também pode haver a sua diminuição através da privação de «liberdade» que pode surgir em razão de processos inadequados - como a violação do direito ao voto ou de outros direitos políticos ou civis-, ou da falta de oportunidade para realizar o que gostariam — também podem ser denominadas de condições, como a fome, analfabetismo-.

O conceito de desenvolvimento humano tem suas origens no pensamento clássico e , em particular, nas ideias de Aristóteles, que acreditava que alcançar a plenitude do florescimento das capacidades humanas é o sentido e fim de todo desenvolvimento. Ford e Lerner (I992, p.49) apresentam um conceito complementar: «o desenvolvimento humano envolve processos de incremento e transformação que através do fluxo de interações entre características atuais da pessoa e os contextos em que está inserida, produz uma sucessão de mudanças relativamente duradouras $[\ldots .$.$] ».$ 
Wolfensohn (I999) defende uma "estrutura de desenvolvimento ampla» com abordagem integrada e multifacetada, visando a um progresso simultâneo em diferentes frentes. Sen (20I0) defende que a plenitude da liberdade requer mais do que suprir com as necessidades básicas, mas requer a inserção do cidadão no meio político interagindo e influenciando nas próprias diretrizes das políticas públicas.

\section{Método da Pesquisa}

A pesquisa caracteriza-se como uma pesquisa de análise documental já que os objetos de análise são os relatórios do Transparency Internacional (TI): "Corruption Perceptions Index», CPI e pela United Nations Development Programme (UNDP): «Human Development Index» (HDI). Ambos os relatórios podem ser obtidos de forma impressa ou digital em seus respectivos endereços eletrônicos.

Primeiramente, foram obtidos os dados do CPI referente a um Quadriênio (2010-20I3). Transparency Internacional, Technical Methodology Note (2OI2): "Corruption Perceptions Index» segue 4 (quatro) etapas: I) seleção de dados, 2) redimensionamento dos dados, 3 ) agregação dos dados redimensionados e 4) análise da medida de incerteza». A pesquisa mede a percepção do grau de corrupção aferido por empresários, analistas de riscos e o público em geral. O Transparency Internacional é uma organização não-governamental que monitora a corrupção no mundo.

O IDH, criado pela ONU no início da década de noventa, tem sido calculado anualmente para diversos países. Foi idealizado para servir como a base empírica dos Relatórios de desenvolvimento humano, responsáveis por monitorar o processo de desenvolvimento mundial. O «Human Development Index» é constituído por 3 pilares: Saúde, Educação e Renda. Esses três fatores são calculados, obtendo-se uma média e, partir de então, é atribuído um valor ao país de acordo com a média obtida.

Também se caracteriza como uma pesquisa quantitativa, uma vez que, a pesquisa tem como proposta a interpretação dos dados dos dois índices citados no período de I (um) Quadriênio, 20I0 a 20I3. O presente estudo buscou analisar, através do coeficiente de correlação de Pearson (r), a seguinte hipótese: «existe uma forte correlação entre corrupção e o desenvolvimento humano». Garson (2009) afirma que correlação é uma medida de associação bivariada (força) do grau de relacionamento entre duas variáveis. Para Moore 
(2007: IOO-IOI), «A correlação mensura a direção e o grau da relação linear entre duas variáveis quantitativas». O estudo também contempla a estatística descritiva, com o cálculo da média, desvio-padrão, amplitude dos índices e histograma. Como ferramenta, foi utilizado o programa computacional Statistical Package for Social Science (SPSS). Em paralelo foi realizado ainda o teste de regressão linear devido a sua capacidade preditiva.

A pesquisa tem como característica a estatística amostral, já que realizou a análise com I7I países, onde o universo contém I93 países reconhecidos, segundo a ONU, correspondendo a uma amostra de $87 \%$. Os I 7 I países foram divididos em 6 macrorregiões, a saber: África Subsaariana (AF), Américas (AM), Ásia-Pacífico (AP), Europa Oriental/Ásia Central (EOr/AC), União Europeia/Europa Ocidental (UE/EOc) e Médio Oriente e Norte Africano (ME/ NA).

\section{Análise dos dados}

Índice de Percepção da Corrupção e Desenvolvimento Humano

Atualmente, o índice de corrupção mais utilizado em pesquisas sobre corrupção é formulado pelo Transparency Internacional (TI), uma organização nãogovernamental de coalização contra a corrupção com sede em Berlim (ALE). A organização chega a esse índice através de survey, aplicados por especialistas no tema e direcionado a pessoas de vários setores de cada país com objetivo de obter a «percepção da corrupção» em cada um dos países.

A amostra do presente estudo contém I7I países, divididos em 6 macrorregiões. África Subsaariana (AF) —Angola, Benin, Botswana, Burkina Faso, Burundi, Camarões, Cabo Verde, República Centro-Africano, Chade, Comores, República do Congo, Costa do Marfim, República Democrática do Congo, Djibouti, Guiné Equatorial, Eritreia, Etiópia, Gabão, Gâmbia, Gana, Guiné, Guiné-Bissau, Quênia, Lesoto, Libéria, Madagáscar, Malaui, Mali, Mauritânia, Maurício, Moçambique, Namíbia, Níger, Nigéria, Ruanda, São Tomé e Príncipe, Senegal, Seicheles, Serra Leoa, África do Sul, Suazilândia, Tanzânia, Togo, Uganda, Zâmbia e Zimbábue; Américas (AM) -Argentina, Bahamas, Barbados, Bolívia, Brasil, Canadá, Chile, Colômbia, Costa Rica, Cuba, Dominica, República Dominicana, Equador, El Salvador, Guatemala, Guiana, Haiti, Honduras, Jamaica, México, Nicarágua, Panamá, Paraguai, Peru, Costa Rica, Santa Lúcia, São Vicente e Granadinas, Suriname, Trinidade e Tobago, Esta- 
dos Unidos, Uruguai e Venezuela; Ásia-Pacífico (AP) —Afeganistão, Austrália, Bangladesh, Butão, Brunei, Camboja, China, Hong Kong, Índia, Indonésia, Japão, Coreia do Sul, Laos, Malásia, Mongólia, Mianmar, Nepal, Nova Zelândia, Paquistão, Papua Nova Guiné, Filipinas, Cingapura, Sri Lanka, Tailândia, Timor-Leste e Vietnã; Europa Oriental/Ásia Central (EOr/AC) —Albânia, Armênia, Azerbaijão, Bielo-Rússia, Bósnia e Herzegovina, Geórgia, Cazaquistão, Quirguistão, Macedônia, Moldávia, Montenegro, Rússia, Sérvia, Tajiquistão, Turquia, Turcomenistão, Ucrânia e Uzbequistão; União Europeia/Europa Ocidental (UE/EOc) - Áustria, Bélgica, Bulgária, Croácia, Chipre, República Tcheca, Dinamarca, Estônia, Finlândia, França, Alemanha, Grécia, Hungria, Islândia, Irlanda, Itália, Letônia, Lituânia, Luxemburgo, Malta, Holanda, Noruega, Polônia, Portugal, Romênia, Eslováquia, Eslovênia, Espanha, Suécia, Suíça e Reino Unido; Médio Oriente e Norte Africano (ME/NA) —Argélia, Bahrain, Egito, Iémen, Emirados Árabe, Irã, Iraque, Israel, Kuwait, Líbano, Líbia, Marrocos, Omã, Catar, Arábia Saudita, Sudão, Síria e Tunísia.

Considerando os dados da ONU, que reconhece 193 territórios como países, a amostra corresponde a $87 \%$ do universo. Os países do estudo foram selecionados a partir do Transparency Internacional (TI) e o United Nations Development Programme (UNPD), que publicam os Índice de Percepção da Corrupção e o Índice de Desenvolvimento Humano, respectivamente.

O Índice de Percepção da Corrupção IPCorr é demonstrado através de uma pontuação atribuída aos países. Essa pontuação varia em uma escala de $\circ$ a Io०, onde o corresponde a um país extremamente corrupto (Highly Corrupt) e ıoo ao país totalmente livre de corrupção (Very Clean). A fim de facilitar a visualização, os países foram substituídos pelas macrorregiões e a pontuação

Tabela 1. Pontuação no Índice de Percepção da Corrupção

\begin{tabular}{|lccccc|}
\hline Região & $\mathbf{2 0 1 3}$ & $\mathbf{2 0 1 2}$ & $\mathbf{2 0 1 1}$ & $\mathbf{2 0 1 0}$ & Média \\
\hline África Subsaariana & 33,50 & 34,35 & 29,92 & 29,28 & 31,76 \\
\hline Américas & 44,88 & 45,59 & 42,39 & 42,91 & 43,94 \\
\hline Ásia-Pacífico & 43,69 & 43,27 & 42,37 & 41,19 & 42,63 \\
\hline Europa Oriental e Ásia Central & 32,72 & 32,72 & 28,42 & 28,33 & 30,55 \\
\hline Médio Oriente e Norte da África & 36,56 & 38,06 & 37,59 & 37,72 & 37,48 \\
\hline União Europeia e Europa Ocidental & 65,19 & 65,1 & 64,79 & 64,52 & 64,90 \\
\hline Fonte: Adaptado do Transparency Internacional - Tl. Disponível em: https://www.transparency.org & \\
\hline
\end{tabular}


de cada país constituiu a média das suas respectivas regiões. No estudo foi analisado o período de um quadriênio $2010 / 2013$, possibilitando uma análise de tendência histórica e correlação entre as variáveis.

A tabela demonstra a média agrupada dos quatro anos analisados e, percebe-se que, dentro da escala, cinco das seis macrorregiões estão abaixo de 50 pontos (ponto médio), ou seja, em situação de média-alta corrupção. Apenas a macrorregião UE/EOc apresenta uma situação «favorável», acima do ponto médio. Porém, deve-se considerar que os países de cada macrorregião possuem pontuações divergentes dentro da escala, portanto, além da média, também foi analisado os respectivos desvios-padrão. Os resultados demonstraram como maior desvio-padrão a região AP 22,59, representando uma alta variação entre as pontuações dos países dessa região, já a região EOr/AC apresenta a menor variação entre as macrorregiões -IO,I7, ou seja, uma menor heterogeneidade entre as pontuações dos países correspondentes.

Destaca-se ainda a variação negativa da macrorregião Médio Oriente/Norte da África, que a partir da perspectiva histórica no período do quadriênio analisado (20IO-20I3), é a única macrorregião com a média menor do que o valor do primeiro ano (20I0) com 0,24 negativos de divergência. Já as demais macrorregiões apresentam uma variação positiva entre 0,38 e 2,48.

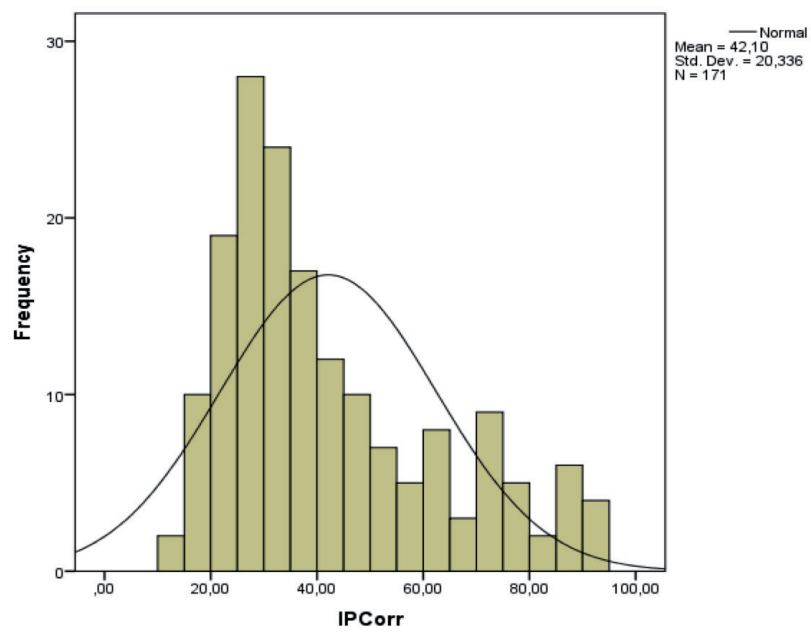

Gráfico 1. Histograma do Índice de Corrupção (Fonte: Adaptado do Transparency Internacional - Tl. Disponível em: https://www.transparency.org). 
O gráfico acima demonstra, graficamente, o resultado dos dados quanto as posições dos países na escala de corrupção proposta pela Transparency Internacional. Identifica-se que a média (mean) do Índice de Corrupção dos países observados (N) é preocupante, tendo em vista que a escala produzida pela Transparency Internacional, onde o representa um um país extremamente corrupto e roo um país totalmente livre da corrupção.

Verifica-se uma amplitude de 82,5 no IPCorr, isso demonstra o abismo entre alguns países, que se torna ainda mais vísivel entre países da região da África Subsaariana e região da União Europeia e Europa Ocidental. Essas extremidades regionalizadas podem ser vistas como uma dicotomia do fenômeno corrupção. Apesar das demais regiões estudas apresentarem pontuação próximas as duas extremidades, as mesmas não possuem uniformidade, ou seja, nas demais regiões encontram-se países muito corruptos e pouco corruptos.

A região AF é caracterizada pela extrema pobreza, elevados índices de analfabetismo e a não ou precária oferta dos serviços públicos básicos (PNUD). Cockcroft (2OI2) ressalta ainda como problemas existentes, os conflitos etnicos com ligações diretas no tráfico de drogas e fraudes financeiras e a instabilidade politica. Todos esses fatores implicam diretamente no desenvolvimento do índividuo pois a privação das capacidades limita a «liberdade substantiva» (Sen, 20I0). Quanto mais a população for desprovida das condições básicas, menor será o interesse por questões mais complexas, porém de grande significância. Rawls (2000) defende a ideia da distribuição dos bens primários para que haja a evolução de estágio da sociedade. Essa concepção justiça social é mais facilmente observado na região EU/EOc, possuindo uma distribuição de renda mais igualitária, um alto indice educacional e a melhor oferta de serviços públicos básicos do mundo.

Através do Índice de Gini é observado uma diferença considerável entre a duas regiões em destaque, enquanto a EU/EOc tem uma média de 30,49, já a região AF tem uma média de 4I,77, com a análise de uma regressão linear verifica-se a o relacionamento entre a variável 'IPCorr' (dependente) e a variável 'GINI' (independente).

Diferentemente da escala utilizada no IPCorr e IDH, o índice de Gini tem como como uma condição ideal de total distribuição quando o valor é igual a o e de total desigualdade (concentração total) quando o valor é igual a Ioo.

Primeiramente, é obtido como resultado do grau de significância (p-value) $\circ, 00(\alpha=0,05)$. O grau de correlação 'r' de o,62 apresenta uma força moderada, segundo Dancey e Reidy (2006). Esse valor demonstra a força, linearidade 


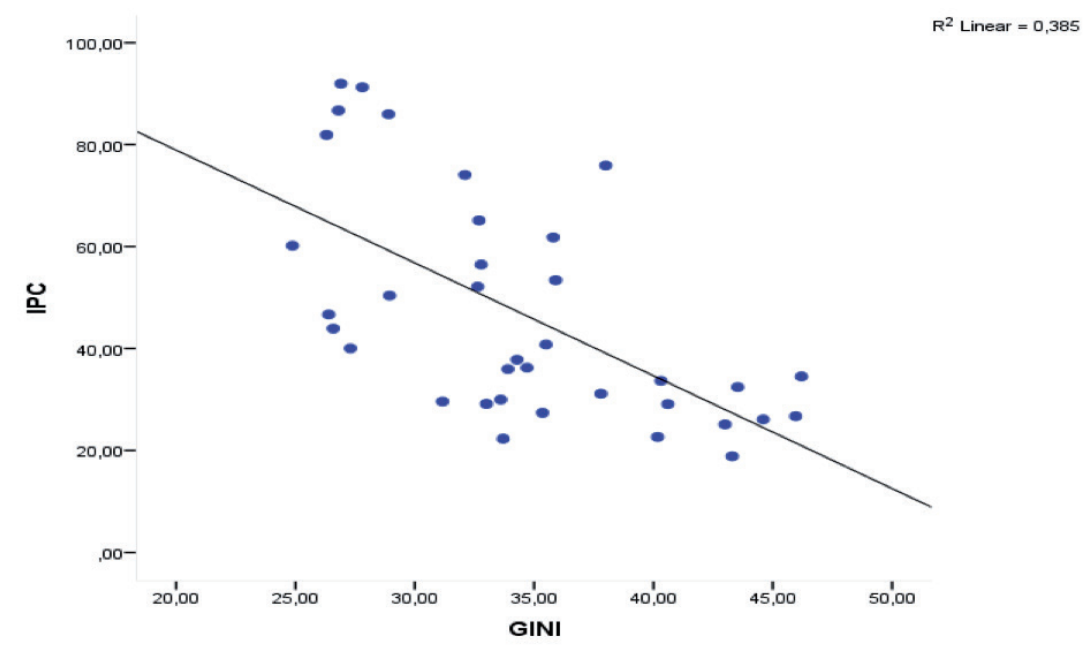

Gráfico 2. Regressão Linear: Corrupção x Desigualdade Econômica (Fonte: Elaboração própria).

e direção das variáveis. Já na análise de regressão linear, tem-se como poder preditivo o valor de 0,385 (r-squared).

Percebe-se então a relevância da desigualdade na distribuição de renda para o aumento da corrupção, onde I ponto no aumento no índice de GINI (maior desigualdade) corresponde a diminuição de 0,385 na escala IPCorr (maior corrupção). Esse resultado corrobora estatisticamente a teoria de Heidenheimer e Johnston (2002), que relaciona abuso de autoridade e corrupção, e nos países onde há uma grande concentração da renda os mais ricos detém naturalmente uma autoridade com pouco ou nenhum limite. Esse cenário torna-se ainda mais crítico em países com várias outras deficiências estruturais e sociais, ou seja, esses demais fatores agravam e aumentam exponencialmente a corrupção. Fica então evidente a necessidade de políticas públicas que viabilizem uma melhor igualdade da renda, contudo, somente ações voltadas a esse propósito não são suficientes para a promoção da justiça social.

Huntington (I973), afirma que quanto mais rico economicamente for um país, mais propenso à corrupção o mesmo estará. Contudo, essa regra não se aplica a todos os países, pois dados do PIB demonstram crescimento econômico de países extremamente corruptos assim como de países com um nível de corrupção baixa, logo o fator riqueza não tem influencia direta nos atos corruptos. Já a variável de distribuição de renda demonstra ser uma variável muito mais consistente para a construção de uma escala ou uma análise pre- 
ditiva. A cultura é um dos pontos cruciais para entendimento e transformação de valores. Inglehart e Baker (2000) comentam que a cultura existente em uma região (povo) pode dificultar ou facilitar o enraizamento natural de valores ou normas que orientem a boa conduta e o cumprimento das normas. Rothestein (20I I) afirma que a transformação da cultura é frágil, contínua e dependente. $\mathrm{O}$ autor lembra que a cultura de privilégios destinada a alguns poucos que ocupam cargos políticos (decision makers) impede o avanço moral e ético de uma sociedade. Outro ponto relevante levantado pelo cientista político, diz respeito à necessidade de uma reforma política organizacional do governo induzindo uma mudança comportamental na população, como exemplo a Suécia - país que passou por um «Big Bang Institucional»-. Com isso, observa-se que a corrupção possui características culturais, mas não é culturalmente determinada. Ou seja, através de uma decisão top-down do governo e uma rígida estrutura administrativa, os rent-seekers perceberam que não havia mais um campo fértil para práticas corruptas. Isso demonstra que o sistema organizacional político-administrativo de um país é de suma importância para a transformação, sendo um catalisador que possui duas forças de direções distintas a depender da governança e accountability. A partir dessa observação podemos então redefinir alguns pontos importantes na composição das variáveis independentes.

Esta segunda tabela demonstra a percepção dos cidadãos comuns quanto a conduta de setores e órgãos tendo em vista o grau de corrupção nos mesmos. Esse índice pode ser utilizado como insight pelos gestores públicos e agente políticos como fonte de informações para tomada de decisão no combate à

Tabela 2. Percepção da Corrupção por Instituição (2013)

\begin{tabular}{|lccccc|}
\hline Região & Part. políticos & Policia & Judiciário & Func. Públicos & Parlam./legis. \\
\hline AF & 2 & 14 & 3 & - & - \\
AM & 9 & 4 & 1 & - & 2 \\
AP & 7 & 9 & 2 & 1 & 3 \\
EOr/AC & 5 & 3 & 3 & 5 & - \\
MO/NA & 4 & 2 & 1 & 1 & - \\
UE/EOc & 16 & - & 4 & - & 1 \\
Total \% & $42 \%$ & $31 \%$ & $14 \%$ & $7 \%$ & $6 \%$ \\
Fonte: Adaptado do Transparency Internacional - TI. Disponivel em: https://www.transparency.org & \\
\hline
\end{tabular}


corrupção de forma direcionada. O resultado da pesquisa mostra-se válido pois demonstra a percepção da população que está cotidianamente interagindo com as instituições pública e/ou privadas.

A organização Transparency Internacional - TI realiza um survey utilizando I 2 (doze) setores e órgãos no questionário e, partir do questionário, o entrevistado atribui notas em uma escala de $\circ$ a ıоo, onde $\circ$ seria um setor ou órgão isento de corrupção e ıoo corresponde a um estágio extremo de corrupção. O questionário elenca os seguintes setores e órgãos: partidos políticos, parlamento/legislativo, militares (exército), ONG’s, mídia, organizações religiosas, organizações privadas, sistema educacional, sistema judiciário, serviços de saúde, polícia e funcionalismo público (administração). Porém, a tabela acima não apresenta as pontuações individuais, mas aponta quantas vezes cada uma das instituições apareceu como o principal «ambiente» de corrupção do país. Mais uma vez, foram utilizadas as macrorregiões devido à grande quantidade da amostra.

A fim de uma melhor análise, foram escolhidos apenas os 5 setores/órgãos com maiores índices de corrupção: partidos políticos, parlamento/legislativo, funcionalismo público (administração), polícia e sistema judiciário. Dentre esses, dá-se o destaque negativo aos partidos políticos - podendo inserir os próprios componentes do partido - que obteve o maior percentual dentre os demais (42\%), sendo $37 \%$ (I 6 apontamentos) correspondente a região da União Europeia e Europa Ocidental - UE/EOc. Outra instituição com um percentual substancial de apontamentos foi a Polícia (I 4 apontamentos), correspondendo a $3 \mathrm{I} \%$ do geral. Os países da África Subsaariana foram os países que mais vezes apontaram a instituição policial como a mais corrupta (44\%).

Observa-se que os partidos políticos e judiciário foram apontados, pelo menos uma vez, em todas as macrorregiões como instituições mais corruptas, isso mostra um certo grau de homogeneidade quanto a institucionalização da corrupção nos países. A tabela demonstra a fragilidade de vários organismos públicos que deveriam trabalhar em prol da população. Assim, a accountability horizontal e vertical mostram-se ainda mais necessárias nesses contextos, pois apenas com transparência, controle e punibilidade é possível iniciar o processo de mudanças e tornar a administração pública sem disfunções e com uma maior efetividade.

Apesar dos apontamentos dos resultados quanto ao nível de corrupção, Cockcroft (20I2) ressalta que a corrupção também está presente no setor privado, nas mais diversas áreas: indústria, comércio e serviços. Contudo, devido 
Tabela 3. Índice de Corrupção x Índice de Desenvolvimento Humano

\begin{tabular}{|c|c|c|c|c|c|c|c|c|c|}
\hline \multirow[b]{2}{*}{ Regiões } & \multicolumn{2}{|c|}{2013} & \multicolumn{2}{|c|}{2012} & \multicolumn{2}{|c|}{2011} & \multicolumn{2}{|c|}{2010} & \multirow{2}{*}{$\begin{array}{l}\text { Correlação } \\
\text { R - Pearson }\end{array}$} \\
\hline & IPCorr & IDH & IPCorr & $\mathrm{IDH}$ & IPCorr & IDH & IPCorr & $\mathrm{IDH}$ & \\
\hline $\mathrm{AF}$ & 33,50 & 0,5 & 34,35 & 0,45 & 29,92 & 0,46 & 29,28 & 0,42 & 0,68 \\
\hline AM & 44,88 & 0,73 & 45,59 & 0,73 & 42,39 & 0,72 & 42,91 & 0,70 & 0,70 \\
\hline AP & 43,69 & 0,69 & 43,27 & 0,67 & 42,37 & 0,65 & 41,19 & 0,64 & 0,89 \\
\hline EOr/AC & 32,72 & 0,72 & 32,72 & 0,72 & 28,42 & 0,71 & 28,33 & 0,67 & 0,51 \\
\hline $\mathrm{MO} / \mathrm{NA}$ & 36,56 & 0,73 & 38,06 & 0,71 & 37,59 & 0,69 & 37,72 & 0,68 & 0,76 \\
\hline UE/EOc & 65,19 & 0,86 & 65,1 & 0,87 & 64,79 & 0,86 & 64,52 & 0,84 & 0,78 \\
\hline
\end{tabular}

a menor visibilidade dada pela accountability social (mídia) e a dificuldade no acesso de informações dessas empresas, dificultam a mensuração da participação dessas empresas em atos corruptos.

A tabela 3 demonstra o confronto entre o Índice de Percepção da Corrupção - IPCorr e o índice do Desenvolvimento Humano - IDH. A análise foi realizada com uma perspectiva correlação entre os países ano a ano a um método de estatística descritiva e correlação: Desvio Padrão e Coeficiente de Correlação Linear de Pearson (r). O método consiste em analisar a correlação entre duas variáveis $(x, y)$ que, no presente estudo refere-se aos índices já citados. O objetivo da análise consiste em detectar qual o grau de correlação entre a corrupção e o desenvolvimento humano.

Utilizando o cálculo de Pearson, obtivemos $r$ de correlação de cada macrorregião, com objetivo de demonstrar que dependendo da quantidade e tipo da amostra o resultado pode apresentar uma variação substancial, prejudicando a análise do fenômeno, resposta de hipóteses e a construção inferências. Por isso, é importante levantar o maior número possível de elementos para que a composição da análise retrate o quadro real. «the sampling distribution of Pearson's $r$ does not approximate normality for small samples. When $\mathrm{n}$ increases, distributions will aproximate normal more slowly when $\neq 0$ then when =0» (Chen e Popovic, 2002, p. I 5 ). Por exemplo, caso fossem adotados apenas os países da região Ásia-Pacífico, o resultado seria uma forte correlação $(0,88)$, mas se fossem adotados apenas os países pertencentes à região Europa Oriental e Ásia Central, o resultado seria uma correlação média $(0,5$ I), ou seja, a 
escolha de pequenas amostras dentro de um universo pode tornar a pesquisa tendenciosa e falha.

Primeiramente, demonstraremos os resultados da média da correlação de Pearson ( $\mathrm{r}$ ) em uma análise entre países no quadriênio 20I0-20I3. Também foram evidenciados os resultados das correlações de cada macrorregião propositalmente pelos motivos já citados no parágrafo anterior.

Os dados dos países em questão foram levantados e compilados para obtenção do coeficiente de correlação linear de Pearson (r). A correlação obtida foi $r=0,72$. Dancey e Reidy (2005) apontam a seguinte classificação: $r=0,10$ até $0,3 \circ$ (fraco); $\mathrm{r}=0,40$ até 0,6 (moderado); $\mathrm{r}=0,70$ até I (forte). Também foi obtido of de significação $=0,00$. Menor do que 0,05 , ou seja, é significativa. Com esses dados, mostra-se que há uma associação e linearidade forte e positiva entre os índices (corrupção e desenvolvimento humano). Vale lembrar que a escala de Pearson varia entre I e -I. Além disso, os resultados apresentaram um $\mathrm{r}^{2}=0,525$. Ou seja, isto significa que $52,5 \%$ da variável dependente consegue ser explicado pelo regressor presente no modelo.

Através do gráfico pode-se observar a tendência positiva da correlação, como já demonstrada. Além disso, o gráfico facilita a compreensão do valor de $\mathrm{r}(0,72)$, pois quanto mais próximos estiverem os pontos da reta traçada, maior será o grau de correlação e quanto mais distante, menor será a. Ou seja, apresenta uma correlação forte, mas não perfeita quanto a associação e linearidade. Como exemplo, pode-se adotar as extremidades de uma das variáveis para análise, por exemplo: no eixo (y) - IDH, observa-se que a pontuação da

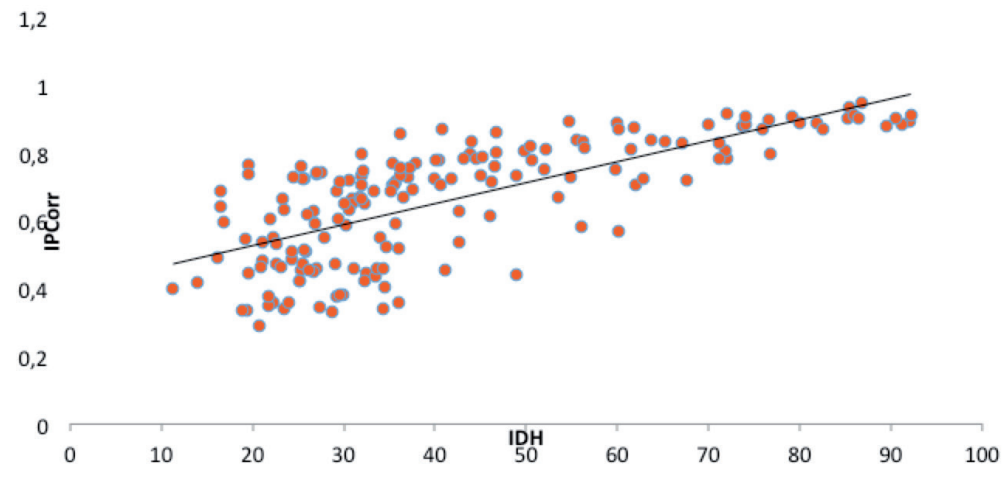

Fonte: Elaboração própria

Gráfico 3. Diagrama: Coeficiente de Correlação Linear de Pearson (Fonte: Elaboração própria). 
última amostra (República Democrática do Congo) equivale a 0,32 e localizase entre os últimos no IPCorr, representando alto nível de corrupção, mas para que se torna uma correlação perfeita (I), o IPCorr também deveria ser o último, assim como o IDH. Isso também acontece no outro extremo que equivale a 0,95 no IDH (Noruega) e localiza-se entre os primeiros no IPCorr, baixo nível de corrupção, mas a correlação perfeita somente aconteceria com o IPCorr em 90,5 - I ${ }^{\circ}$ lugar -. Esses são exemplos que demonstram o porquê da correlação forte, mas não perfeita.

Foi observado ainda a amplitude dos dois (2) índices em questão. O IDH apresentou como último e primeiro valor 0,32 a 0,95 , respectivamente. Amplitude de 0,63 . Ou seja, os países elencados perpassam do desenvolvimento humano baixo ao desenvolvimento humano muito alto, segundo a ONU. Já o IPCorr apresenta como último e primeiro valor 8 e 90,5, respectivamente. Amplitude de 82,5. Ou seja, os países elencados partem de um baixo nível de corrupção ao nível muito alto de corrupção, segundo a escala do TI. O resultado da amplitude demonstra o contraste existente entre os vários países do mundo.

No presente estudo foi preciso eliminar um (I) país - Jordânia, pois apresentou uma variação acentuada no eixo y, fora dos padrões das demais amostras, comprometendo a análise do fenômeno. Esse tipo de amostra configurase com um outlier, um ponto destoante dos demais. Tanto a direção quanto a magnitude do coeficiente são afetadas pela presença de observações destoantes. Outliers podem gerar correlações espúrias e/ou esconder associações reais (Figueiredo Filho \& Silva Junior, 2009).

Os dados revelaram que apenas 53 países alcançam o desenvolvimento humano muito alto (condição ideal), sendo 30 desses países localizadas na União Europeia e Europa Ocidental - UE/EOc e, negativamente, existem 40 países na zona do desenvolvimento humano baixo, sendo 33 deles localizados na África Subsaariana - AF. Já no IPCorr, como baixo nível de corrupção foi adotado a pontuação a partir de 70 pontos dentro da escala da TI, o resultado foi que apenas 25 países possuem um baixo nível de corrupção, sendo I 3 deles localizados na UE/EOc e, negativamente, existem 53 países com alto nível de corrupção, sendo 22 deles localizados na AF.

\section{Considerações Finais}

O presente estudo buscou analisar a seguinte hipótese: «há uma forte correlação entre a corrupção e o desenvolvimento humano». Como objeto de análi- 
se foram escolhidos I7 I países localizadas nos seis (6) continentes. A amostra, que abrange $87 \%$ do universo, apresentou um alto nível de aproximação da realidade e que o resultado obtido pelo coeficiente de correlação de Pearson (r), possivelmente, apresentará um resultado similar em uma análise dos 193 países ( Iо०\%). Além disso, é importante ressaltar que a amostra não deve ser tendenciosa e, por isso, a estratificação pode auxiliar ou comprometer a pesquisa. Porém, quanto maior o número de países, maior será o número de variáveis, elementos, indicadores que pode influenciar no resultado: cultura, governo, sistema econômico, educação dentre outros.

Devido à complexidade e extensão do assunto, não foi levada em consideração maiores particularidades dos países, por isso foi definido que os índices de Percepção da Corrupção do TI e Desenvolvimento Humano do PNUD seriam a base de dados para a análise proposta. A padronização da obtenção desses dados e a possibilidade de verificação da metodologia aplicada dá credibilidade aos dados fornecidos por essas organizações. Para chegar aos resultados apresentados foi preciso aplicar o Coeficiente de Correlação Linear de Pearson. Contudo, outros cálculos e análises foram realizados, demonstrandose pertinentes, como: Média, Desvio Padrão, Amplitude, Grau de Significância e Regressão Linear. Todos esses métodos foram imprescindíveis para a validação, conclusão e melhor compreensão do fenômeno.

Ressalta-se que ambos os índices - IDH e IPCorr, são índices compostos por várias outras variáveis e que uma análise bivariada entre ambas consiste em uma análise multivariada "sintetizada», com isso, os dados analisados permitem, com maior credibilidade, o pesquisador constatar resultados válidos de inferência.

Como resultados, que auxiliam na corroboração da hipótese, observa-se:

- A maioria dos países de desenvolvimento humano 'muito alto' está localizada na macrorregião União Europeia/Europa Ocidental que, por sua vez, possui os menores índices de corrupção no mundo, a partir de uma perspectiva de proporcionalidade.

- A maioria dos países de desenvolvimento humano 'baixo' está localizada na macrorregião África Subsaariana que, por sua vez, possui os maiores índices de corrupção no mundo, a partir de uma perspectiva de proporcionalidade.

- O Coeficiente de Correlação Linear de Pearson, variou entre médio e forte grau de correlação mesmo em menores amostras estratificadas, 
0,5I a o,88. Já a correlação dos I7 I países foi de o,72, uma correlação forte e positiva, segundo Dancey e Reidy (2005).

- Com a eliminação de um (I) país - Jordânia -, que se encontrava como ponto de distorção no eixo y (outlier), o grau de correlação aumentou drasticamente.

- Quanto as instituições e setores, constatou-se que a população tem uma grande desconfiança sobre a legalidade dos atos dessas instituições. E, um dos reflexos disso pode ser visto no «termômetro» de confiança publicado pelo Transparency Internacional. $\mathrm{O}$ resultado apresenta um cenário desfavorável com desafios de mudança organizacional e comportamental.

Essa análise quantitativa dos dados levanta ainda mais questões sobre o tema e, sendo a correlação considerada forte - mas não perfeita (I) - é necessário que se observe quais são as demais variáveis que influenciam negativamente no desenvolvimento humano, de forma à auxiliar a construção de um instrumento de análise. Isso também é válido para a corrupção, já que a metodologia apresenta alguns «gaps» a serem preenchidos. Como meio de validação, a abordagem qualitativa do impacto da cultura sobre a corrupção demonstrou o povo, apesar da sua direta influência sobre os fenômenos sociais, a mesma não possui força para modificar drasticamente uma cultura enraizada de corrupção; apenas com apoio ou iniciativa do poder público (Estado) seria possível a mudança de cenário.

Ao analisar as instituições, percebe-se claramente a associação de algumas dessas instituições com a corrupção, sendo necessário um estudo de "reforma» política e cultural. Apesar da limitação do estudo, os dados verificados foram suficientes para análise da hipótese e validar, de forma quantitativa, as teorias e afirmações de muitos estudiosos que defendem o combate à corrupção por ser um dos fatores de geração de injustiça social, privação das liberdades e retardamento no desenvolvimento humano. É visto que as duas variáveis são inversamente proporcionais, ou seja, na medida em que a corrupção aumenta o desenvolvimento humano diminui e vice-versa, porém, a relação apesar de forte, não é perfeita. Todo o processo de construção de entendimento do fenômeno deve ser analisado contextualmente levando em consideração todos os aspectos pertinentes que existem em cada região.

A participação social torna-se um catalisador para o processo de mudança e combate à corrupção pois a accountabililty sustenta-se em um tripé: accou- 
ntability vertical (cidadãos comuns), horizontal (governo) e social (grupos organizados). A pressão exercida pelo povo faz com que os gestores públicos e agentes políticos busquem ferramentas e métodos fundamentais para o auxílio na busca de uma sociedade mais justa com liberdade, igualdade, democracia e desenvolvimento. Os instrumentos de accountability mostram-se ainda mais importante na tentativa de combate e repressão à corrupção. Percebe-se quanto menos instrumentos de accountability, maior a possibilidade de atos corruptos.

De certa forma os tipos de accountability mantêm uma interdependência de efetividade; geralmente os atos corruptos surgem a partir de denúncias divulgadas pela mídia, posteriormente, os órgãos públicos competentes utilizam as informações veiculadas começam o processo de accountability horizontal e através dos relatórios de constatações a população pode exercer com maior eficácia o direito garantido por lei de accountability vertical. É válido lembrar que accontability vertical não é apenas exercida através do voto, mas por demais mecanismos legais que conferem à população o poder de influenciar decisões que afetam diretamente a sociedade.

Como contribuição para trabalhos futuros, o presente estudo fornece a corroboração da hipótese: «Há uma forte correlação entre corrupção e desenvolvimento humano». Poderiam ser pesquisadas, a posteriori, quais as demais variáveis que estão envolvidos nos dois processos, assim como uma análise entre países e/ou macrorregiões mais aprofundada em características particulares que possam explicar perfeitamente o fenômeno da corrupção.

\section{Referências}

Alves, M. S. D. (2009). A corrupção promove o social? Uma análise à luz da teoria dos sistemas. Revista CAAP. Belo-Horizonte, Jul-dez.

Aristóteles. (2012). A Política. São Paulo: Martim Claret.

Avritzer, L. y otros. (2008). Corrupção: Ensaios e Críticas. Belo Horizonte: Ed. UFMG.

Behn, R. D. (200I). Rethinking Democratic Accountability. Brookings Institution Press. Washington, D.C.

Bobbio, N. (I986). O futuro da democracia. Uma defesa das regras do jogo. São Paulo: Paz e Terra.

Chen, P. Y. \& Popovich, P. M. (2002). Correlation: parametric and nonparametric measures. London: Sage. 
Cockcroft, L. (2012). Global Corruption: Money, Power and Ethics in the Modern World. United Kingdom: I.B.Tauris \& Co. Ltd.

Cohen, J., Cohen, P., West, S. G., \& Aiken, L. S. (2003). Applied multiple regression/correlation analysis for the behavioral sciences. ( $3^{\circ}$ ed.). Mahwah, NJ: Lawrence Erlbaum Associates.

Dahl, R. A. (200I). Sobre a Democracia. Tradução de Beatriz Sidou. Brasília: Universidade de Brasília.

Dancey, C. \& Reidy, J. (2006). Estatística Sem Matemática para Psicologia: Usando SPSS para Windows. Porto Alegre, Artmed. .

Figueiredo Filho, D. B.; Silva Júnior, J. A. D. (2009). Desvendando os Mistérios do Coeficiente de Correlação de Pearson (r). Revista Política Hoje, I 8 (8): II 5-I 46.

Ford, D.h. \& Lemer, R.M. (1992). Developmental systems theory: An integrative approach. London: Sage Publications.

Garson, G. D. (2008). Statnotes: Topics in Multivariate Analysis. From North Carolina State University Public Administration Program http://faculty. chass.ncsu.edu/garson/PA765/statnote.htm.

Gingerich, D. (2006). Corruption in general equilibrium: political institutions and bureaucratic performance in South America. Tese de Doutorado. Cambridge, Mass. Tese de Doutorado

Habermas, J. (2002). A inclusão do outro: estudos de teoria política. Tradução de George Sperber. São Paulo: Loyola,

Heffernan, W. C.; Kleinig. J. (2004). Private and Public Corruption. United States of America, Rowman \& Littlefield Publishers.

Heidenheimer, A. J. (1970). A Political Corruption. Readings in comparative analysis. New York, Hold, Rinehartand Winstow.

Heidenheimer, A. J.; Johnston, M. (2002) Political corruption: concepts and contexts. $3^{\circ}$ ed. New Jersey.

Heimann, F.; Foldes, A.; Bathory, G. (20I4). Exporting Corruption. Transparency Internacional.

Huntington, S. P. (1973). Political Order in Changing Societies. $7^{\circ}$ Ed. Yale University.

Inglehart, R; Baker, W. (2000). Modernizarion, cultural change, and the persistence of tradicional values. American Sociological Review, 65 (I): 36.

Klitgaard, R. (1994). A corrupção sob controle. Traduzido por Octavio Alves Filho. Rio de Janeiro: Jorge Zahar.

Maquiavel. (2009). O Príncipe. São Paulo: Madras. 
Matias-Pereira, J. (2009). Curso de Administração Pública. São Paulo: Atlas.

Miranda, L. F. V. (2009). Definindo e Medindo Corrupção: Métodos.Fórum Brasileiros de Pós-Graduação em Ciência Política. Belo Horizonte - MG

Moore, D. S. (2007). The Basic Practise of Statistics. New York: Freeman.

Motta, F. C. P. (2004). Introdução à Organização Burocrática. São Paulo: Thomson Pioneira.

Nogueira, M. A. (2005). Um Estado para a sociedade civil. São Paulo: Cortez.

Noonan, J. T. (1987). Bribes. Berkeley: University of California Press.

O’Donnel, G.(I998). Accountability Horizontal e novas poliarquias. Lua Nova: Revista de Cultura Política, 44.

Pareto, V. (1984). Tratado de Sociologia Geral. São Paulo: Ática.

Rawls, J. (2000). Uma teoria da Justiça. Traduzido por Almiro Pisetta e Lenita M. R. Esteves. São Paulo: Martins Fontes.

Rose-Ackerman, S. (1999). Corruption and Government. Causes, Consequences, and Reform. Cambridge: Cambridge University Press.

Rothestein, B. (20II). The Quality of Government. Corruption, Social Trust and Inequality in International Perspective. University of Chicago Press.

Sen, A. (20IO). Desenvolvimento como liberdade. Tradução de Laura Teixeira Motta. São Paulo: Companhia das letras.

Wallin, C. (20I4). Um país sem excelências e mordomias. São Paulo: Geração.

Weber, M. (1962). Basic Concepts in Sociology. Translated and with an Introduction by H. P. Secher. New York: Philosophical Library.

Weffort, F. C. (2004). Os clássicos da política. I $3^{\circ}$ ed. São Paulo: Ática.

William C. H.; Kleinig, J. (2004). Private and Public Corruption. Rowman \& Littlefield.

Wolfensohn, J. D. (1999). A proposal for comprehensive development framework. World Bank.

\section{Sobre el autor}

Junior Sarmiento es graduado de Ciências Contábeis en la Universidade Federal de Alagoas; posee un Mestrando em Administração Pública por la Universidade Federal de Alagoas. Actualmente se desempeña como Técnico Servidor Público Federal en la Universidade Federal de Alagoas. 